\title{
BMJ Open Positive percentages of urine morphine tests among methadone maintenance treatment clients with HIV/AIDS: a 12-month follow-up study in Guangdong Province, China
}

Xiaofeng Luo, ${ }^{1}$ Xiao Gong, ${ }^{1}$ Peizhen Zhao, ${ }^{2}$ Xia Zou, ${ }^{1}$ Wen Chen,,${ }^{1}$ Li Ling ${ }^{1}$

To cite: Luo X, Gong X, Zhao P, et al. Positive percentages of urine morphine tests among methadone maintenance treatment clients with HIV/ AIDS: a 12-month followup study in Guangdong Province, China. BMJ Open 2017;7:e014237. doi:10.1136/ bmjopen-2016-014237

Received 16 September 2016 Revised 10 March 2017 Accepted 13 March 2017
CrossMark

${ }^{1}$ Faculty of Medical Statistics and Epidemiology, School of Public Health, Sun Yat-sen Center for Migrant Health Policy, Sun Yat-Sen University, Guangzhou, China

${ }^{2}$ Guangdong Provincial Center for Skin Disease and STI Control, Guangzhou, China

Correspondence to Dr Li Ling;

lingli@mail.sysu.edu.cn

\section{ABSTRACT}

Objective We aimed to assess the positive percentages of urine morphine tests and correlates among methadone maintenance treatment (MMT) clients with HIV/AIDS in Guangdong, China.

Setting Fourteen MMT clinics located in nine cities of Guangdong were chosen as study sites.

Participants In this study, we reviewed 293 clients with opioid dependence, who were HIV seropositive, 18 years or older, provided informed consent and had at least 10 records of urine morphine tests during the study period.

Primary and secondary outcome measures The positive percentages of urine morphine tests were calculated and underlying predictors were estimated. Results The highest positive percentage (95.9\%) was observed in the first month. After excluding the highest percentage in the first month, the average positive percentage was $40.9 \%$ for month 2 to month 12 . Positive percentages of urine morphine tests that were $<20 \%$, $20-60 \%$ and $>80 \%$ were $25.4 \%, 36.1 \%$ and $38.5 \%$ respectively. Lower percentages of continued heroin use were associated with being young $\left(\mathrm{OR}_{\leq 30}=0.31,95 \%\right.$ Cl 0.12 to $0.78 ; \mathrm{OR}_{31}=0.44,95 \% \mathrm{Cl} 0.20$ to 1.00 ), and financial sources depending on family or friends $(\mathrm{OR}=0.55$, $95 \% \mathrm{Cl} 0.32$ to 0.93$)$. Higher percentages of continued heroin use were associated with being unemployed (OR=1.99, 95\% $\mathrm{Cl} 1.13$ to 3.49$)$ and poor MMT attendance $\left(\mathrm{OR}_{<20 \%}=3.60,95 \% \mathrm{Cl} 1.55\right.$ to $8.33 ; \mathrm{R}_{20 \%}=2.80,95 \% \mathrm{Cl}$ 1.48 to 5.33 ).

Conclusions High positive percentages of urine morphine tests remain prevalent among MMT clients with HIV/AIDS in Guangdong. The present findings have implications for taking effective measures to facilitate attendance in order to decrease heroin use and ultimately improve the effectiveness among these sub-group MMT clients.

\section{INTRODUCTION}

In China, illicit drug use has increased dramatically since the 1980s. ${ }^{1}$ Cumulatively, there were 2.95 million drug users registered by the end of 2014 and 480000 new registrations in 2014 nationwide. ${ }^{2}$ Although China has recently experienced a significant

\section{Strengths and limitations of this study}

- This is a long-term consecutive study specifically designed to examine concurrent heroin use among HIV-positive MMT clients in China.

- This study mainly focused on positive percentages of urine morphine tests among HIV-positive MMT clients in China.

- Self-reported data are subject to recall bias or deliberate concealment.

- China is experiencing a significant increase in the use of new drugs, but this study did not consider this.

- We only examined the percentages of heroin use during the first 12 months after receiving MMT due to the limited sample size and high dropout.

increase in the use of new-type drugs, heroin still remains the major illicit drug used. ${ }^{2}$ The earliest HIV case was identified among intravenous drug users (IDUs) in Southern Yunnan province in $1989 .{ }^{3}$ The early spread of HIV epidemics in China was mainly attributed to intravenous drug use. ${ }^{4}$ As of 2013, 437000 people were living with HIV/AIDS in China (including 263000 people living with HIV and 174000 with AIDS), accounting for $0.033 \%$ of the total population; and sentinel surveillance data showed the HIV/AIDS prevalence was $6.3 \%$ among IDUs. ${ }^{5}$

Globally, methadone maintenance treatment (MMT) is the most widely used pharmacological treatment for opioid dependence. China has operated an MMT programme as a national strategy to combat the joint threat of drug use and HIV/ AIDS since $2004 .^{6}$ For decades, the MMT programme has achieved crucial effectiveness not only in reducing heroin use $^{7}$ but also in preventing the spread of HIV. ${ }^{8}$ Meanwhile, studies have shown that MMT is 
beneficial in reducing drug-related criminal activities ${ }^{10}$ and drug-related mortality. ${ }^{11}$ In addition, for HIV-positive individuals, MMT could facilitate adherence to antiretroviral therapy (ART). ${ }^{12}$ By the end of April 2015, China had 767 MMT clinics in 28 provinces across the nation, serving nearly 190000 clients. ${ }^{13}$

However, many clients did not completely abstain from heroin and exhibited continued heroin use while on MMT. ${ }^{14-17}$ Continued heroin use could lead to negative MMT treatment outcomes among clients. ${ }^{18}$ There is still a high mortality rate among people addicted to heroin, even those on MMT. ${ }^{19}$ Drug overdose remains the most common cause of death among MMT clients. ${ }^{20}$ After a period of abstinence via MMT, heroin tolerance of clients decreases, thusoverdose may become more prevalent. ${ }^{21}{ }^{22}$ Individuals with HIV/AIDS are a special group among MMT clients. A meta-analysis showed that HIV seropositivity would increase the mortality risk of overdose. ${ }^{23}$ In addition, continued heroin use would decrease the retention rate among MMT clients with HIV/AIDS. ${ }^{24}$ Therefore, heroin use deserves more attention among MMT clients with HIV/AIDS. To date, limited data are available on heroin use among MMT clients with HIV/ AIDS in China ${ }^{1425}$ and data about the higher percentages of heroin use are even less. To fill this gap, this study examines the higher percentage of heroin use among MMT clients with HIV/AIDS in Guangdong.

\section{METHODS}

\section{Ethics statement}

The Institutional Review Board (IRB) of the School of Public Health (Sun Yat-sen University, Guangzhou, China) reviewed and approved the study protocol. All study participants were asked to provide written informed consent.

\section{Study site and participants}

Guangdong, located on the southern coast of China, is one of the most developed provinces. However, Guangdong also has some of the highest figures for drug users and people with HIV/AIDS: cumulatively it has 48718 HIV-positive cases, ranking fifth among the provinces in China as of October 2014; ${ }^{26}$ in addition, it has one-sixth of totally registered drug users in China. ${ }^{27}$

This study was conducted in 14 MMT clinics located in nine cities of Guangdong (according to whether the 1-year retention rate is above or below $50 \%$, the 61 MMT clinics were divided into two groups, and seven clinics were randomly selected from each group ${ }^{28}$ ). We got permission and authorisation to use and retrieve some of the data for the selected MMT clinics from the Chinese National MMT programme data system. In this study, participants were eligible if they were (1) diagnosed with opioid dependence according to the International Classification of Diseases (10th revision); (2) 18 years or older; (3) tested to be HIV-positive at entry; (4) able to provide informed consent; and (5) had at least 10 records of urine morphine tests.

In this study, 'dropout' was defined as a participant failing to continue MMT for 14 consecutive days. ${ }^{28}$ Based on whether dropout happened before 12 months post MMT initiation, the study period could be classified into two categories: one was defined as the duration between enrolment and dropout, the other was defined as the duration between enrolment and the end of the first 12 months.

\section{Measures}

\section{Self-reported risk behaviours}

At admission, as well as at 6 and 12 months, each participant was requested to complete a questionnaire covering demographic characteristics, drug use history including injecting drugs and sharing needles/equipment, sexual activity history, and condom use status.

A client was regarded as having corresponding risk behaviours during the study period if he/she reported those behaviours either at the 6-month or 12-month interview (ie, drug use behaviours including injecting drugs and sharing needles/equipment; and risky sexual activities including multiple sexual partners, inconsistent condom use and sex trade for drugs).

\section{Methadone maintenance doses and attendance}

In China, to ensure MMT security, clients are forbidden to take methadone outside the clinic. Once enrolled in MMT, the clients must go to the clinic daily during consultation hours to take the prescribed doses of methadone under the supervision of clinic staff, and the daily doses and date are routinely recorded in the national unified MMT management system. The treatment cost is RMB 10 Yuan (US\$1.5) per day regardless of the client's intake doses and times.

The average maintenance dose was obtained via computing the mean daily prescribed dose (the first month's doses were excluded because during the first month the doctor adjusts the dose so that it is appropriate for the client; usually the starting dose is small, $20-40 \mathrm{mg}$ per day, and it will gradually increase to the required amount).

The percentage of MMT attendance was calculated based on the proportion of days that a client actually received the doses over the study period.

\section{Positive percentages of urine morphine tests during the study period}

A positive urine morphine test generally means heroin use by the client within the last few days. Urine-based morphine tests were performed monthly on a random day during the study period.

As mentioned above, there exists an MMT dose adjustment stage for newly enrolled clients. During this stage, most clients often use opioids to adjust themselves to MMT. Therefore, the results of urine morphine tests in 
the first month were excluded from calculation of heroin use and percentages in our study.

A client was recognised as a heroin user as long as any urine morphine test result was positive during the 12 months.

The percentage of heroin use was calculated based on the number of positive urine morphine tests and the total number of urine tests within 12 months.

Based on the urine morphine tests, the clients were grouped as 'urine morphine $(+)^{\prime}$ and 'urine morphine (-)'. Additionally, the positive percentages were grouped as $<20 \%, 20-60 \%$ and $>60 \%$ based on the data distribution.

\section{HIV and urine morphine tests}

Except for those who were already confirmed as HIV-positive prior to this study, each client was invited to receive HIV testing. HIV infection status was screened using an ELISA technique (Beijing BGI-GBI Biotech Co Ltd, Beijing, China). Positive blood specimens for HIV were confirmed using a Western blot assay (Abbott, MP Biomedicals, LLC, Singapore) by the local Centres for Disease Control (CDC). According to related national guidelines, pre-test and post-test counselling services were provided.

Random urine morphine status was screened using a Morphine Diagnostic Kit (Colloidal Gold) technique (ABON Biopharm Co Ltd, Hangzhou, China).

\section{Statistical analysis}

Statistical analyses were performed using SPSS 17.0 for Windows (SPSS Inc, Chicago, Illinois, USA). Categorical variables were described with percentages. Multivariate ordinal logistic regression analysis was conducted to predict higher percentages of heroin use from baseline information, including demographic data, drug use and multiple sex partners, as well as average maintenance dose and percentages of MMT attendance during the study period among the MMT clients with HIV/AIDS. Any $p<0.05$ was considered to be statistically significant.

\section{RESULTS}

\section{Study participants and demographic characteristics}

Among the 293 participants, $16.0 \%$ were older than 40; $91.5 \%$ were men; $99.3 \%$ were ethnic Han (China's predominant ethnic group); $54.3 \%$ were never married; $21.8 \%$ just had elementary or lower education; $68.9 \%$ were unemployed; and $64.2 \%$ obtained financial sources from their family or friends (table 1 ).

\section{Heroin use and multiple sexual partners at baseline}

table 1 presents baseline information on heroin use. Of the participants, $77.8 \%$ had used heroin for more than 10 years; $59.4 \%$ of participants used heroin at least three times daily on average; the vast majority $(98.6 \%)$ used powdered heroin and $99.0 \%$ ever administered drugs by injection. Among the IDUs, $56.6 \%$ ever shared intravenous needles. Only $13.7 \%$ never met the peer users. Of these participants, $21.5 \%$ had had sexual activity with multiple sexual partners (table 1).

\section{Average maintenance doses and attendance}

Among all participants, $46.8 \%$ had received doses below $60 \mathrm{~mL}$ and the average maintenance dose was $(67.5 \pm 28.7)$ $\mathrm{mL}$.

In addition, MMT attendance of $10.6 \%$ of participants was less than $20 \%$ and in only $40.6 \%$ was it over $80 \%$ (table 1).

\section{Positive percentages of urine morphine tests during the study period}

Between 2006 and 2012, there were 3471 urine morphine tests performed and 1580 were positive $(45.5 \%)$. The highest positive percentage was observed in the first month $(95.9 \%)$, then it remained as high as between $39.3 \%$ and $53.6 \%$ for month 2 to month 12. After excluding the highest percentage in the first month, the average positive percentage was $40.9 \%$ for month 2 to month 12 . The median positive percentage of urine morphine tests was $48.6 \%$ for $2006,48.7 \%$ for $2007,44.0 \%$ for $2008,41.2 \%$ for $2009,43.3 \%$ for $2010,43.4 \%$ for 2011 and $22.5 \%$ for 2012 (table 2). Among the 268 urine morphine $(+)$ clients, positive percentages of urine morphine tests that were $<20 \%, 20-60 \%$ and $>60 \%$ were $25.4 \%, 36.1 \%$ and $38.5 \%$ respectively (table 3 ).

After adjusting for potential confounding variables listed in the table, multiple ordinal logistic regression analysis indicated that a higher percentage of heroin use was independently associated with age, employment status, mainly financial sources and percentage of MMT attendance. Participants who were younger $\left(\mathrm{OR}_{\leq 30}=0.31\right.$, $95 \%$ CI 0.2 to $0.78 ; \mathrm{OR}_{31-35}=0.44,95 \%$ CI 0.20 to 1.00 ), and got money from family or friends $(\mathrm{OR}=0.55,95 \% \mathrm{CI}$ 0.32 to 0.93 ) were more likely to be tested as having lower percentages of heroin use; and those who were unemployed ( $\mathrm{OR}=1.99,95 \% \mathrm{CI} 1.13$ to 3.49 ) and had poor MMT attendance percentages $\left(\mathrm{OR}_{<20}=3.60,95 \% \mathrm{CI} 1.55\right.$ to $8.33 ; \mathrm{OR}_{20}=2.80,95 \%$ CI 1.48 to 5.33 ) were more likely to have higher percentage of heroin use (table 4).

\section{Self-reported high-risk behaviours during the study period}

Among the clients who were urine morphine (+), 99.3\% (266 of 268) and $88.1 \%$ (236 of 268) completed the 6-month and 12-month follow-up interviews respectively. Of the 266 clients who completed at least one follow-up interview, $62.8 \%$ ever used drugs, $85.0 \%$ used intravenous drugs, and $25.4 \%$ ever shared intravenous needles; $63.2 \%$ were sexually active, $29.2 \%$ had sex with multiple sexual partners and $43.5 \%$ never used a condom during sexual intercourse. Also, $14.5 \%$ traded sex for drugs (table 5).

\section{DISCUSSION}

Heroin use among MMT clients has been reported substantially worldwide. ${ }^{1516}$ HIV-positive drug users are a unique subgroup for playing a 'dual bridge' role in HIV transmission. This study is an extension of our previous 
Table 1 Characteristics of the participants $(n=293)$

\begin{tabular}{|c|c|c|c|}
\hline & $\begin{array}{l}\text { Urine morphine(-) } \\
(\mathrm{n}=25)\end{array}$ & $\begin{array}{l}\text { Urine morphine }(+) \\
(\mathrm{n}=268)\end{array}$ & $\begin{array}{l}\begin{array}{l}\text { Total } \\
(n=293)\end{array} \\
\end{array}$ \\
\hline Characteristics & No. $(\% *)$ & No. $\left(\%{ }^{*}\right)$ & No. $\left(\%^{\dagger}\right)$ \\
\hline \multicolumn{4}{|l|}{ Age at baseline (years) } \\
\hline$\leq 30$ & $5(7.5)$ & $62(92.5)$ & $67(22.9)$ \\
\hline $31-$ & $9(10.1)$ & $80(89.9)$ & $89(30.4)$ \\
\hline $36-$ & $7(7.8)$ & $83(92.2)$ & $90(30.7)$ \\
\hline$\geq 41$ & $4(8.5)$ & $43(91.5)$ & $47(16.0)$ \\
\hline \multicolumn{4}{|l|}{ Gender } \\
\hline Male & $25(9.3)$ & $243(90.7)$ & $268(91.5)$ \\
\hline Female & $0(0)$ & $25(100.0)$ & $25(8.5)$ \\
\hline \multicolumn{4}{|l|}{ Ethnic } \\
\hline Han & $25(8.6)$ & $266(91.4)$ & 291 (99.3) \\
\hline Others & $0(0)$ & $2(100.0)$ & $2(0.7)$ \\
\hline \multicolumn{4}{|l|}{ Marital status at baseline } \\
\hline Never married & $17(10.7)$ & $142(89.3)$ & $159(54.3)$ \\
\hline Married currently & $5(5.2)$ & $92(94.8)$ & $97(33.1)$ \\
\hline Others & $3(8.1)$ & $34(91.9)$ & 37 (12.6) \\
\hline \multicolumn{4}{|l|}{ Education level } \\
\hline Elementary or lower & $1(1.6)$ & $63(98.4)$ & $64(21.8)$ \\
\hline Junior high school & $18(9.4)$ & $174(90.6)$ & $192(65.5)$ \\
\hline Senior high school or higher & $6(16.2)$ & $31(83.8)$ & 37 (12.6) \\
\hline \multicolumn{4}{|l|}{ Employed status at baseline } \\
\hline Unemployed & $16(7.9)$ & $186(92.1)$ & $202(68.9)$ \\
\hline Employed & $9(9.9)$ & $82(90.1)$ & $91(31.1)$ \\
\hline \multicolumn{4}{|l|}{ Mainly financial sources at baseline } \\
\hline Family or friends & $19(10.1)$ & $169(89.9)$ & $188(64.2)$ \\
\hline Others & $6(5.7)$ & 99 (94.3) & $105(35.8)$ \\
\hline \multicolumn{4}{|l|}{ Duration of drug use (years) } \\
\hline$\leq 10$ & $3(4.6)$ & $62(95.4)$ & $65(22.2)$ \\
\hline $11-15$ & $12(9.2)$ & $118(90.8)$ & $130(44.4)$ \\
\hline$\geq 16$ & $10(10.2)$ & $88(89.8)$ & $98(33.4)$ \\
\hline \multicolumn{4}{|l|}{ Type of drug use at baseline } \\
\hline Heroin & $25(8.7)$ & $264(91.3)$ & $289(98.6)$ \\
\hline Others & $0(0)$ & $4(100.0)$ & $4(1.4)$ \\
\hline \multicolumn{4}{|l|}{ Intravenous drug use at baseline } \\
\hline Yes & $25(8.6)$ & $265(91.4)$ & $290(99.0)$ \\
\hline No & $0(0)$ & $3(100.0)$ & $3(1.0)$ \\
\hline \multicolumn{4}{|c|}{ Shared needles to inject drugs at baseline } \\
\hline Yes & $11(6.7)$ & $153(93.3)$ & $164(56.6)$ \\
\hline No & $14(11.1)$ & $112(88.9)$ & $126(43.4)$ \\
\hline \multicolumn{4}{|c|}{ Average times of drug use per day at baseline } \\
\hline$\leq 2$ & $10(8.4)$ & $109(91.6)$ & $119(40.6)$ \\
\hline$\geq 3$ & $15(8.6)$ & $159(91.4)$ & $174(59.4)$ \\
\hline \multicolumn{4}{|l|}{ Multiple Sex partners at baseline } \\
\hline Yes & $4(6.3)$ & $59(93.7)$ & $63(21.5)$ \\
\hline
\end{tabular}


Table 1 Continued

\begin{tabular}{llll}
\hline & $\begin{array}{l}\text { Urine morphine(-) } \\
(\mathbf{n = 2 5 )}\end{array}$ & $\begin{array}{l}\text { Urine morphine (+) } \\
(\mathbf{n = 2 6 8 )}\end{array}$ & $\begin{array}{l}\text { Total } \\
(\mathbf{n}=\mathbf{2 9 3})\end{array}$ \\
\cline { 2 - 4 } Characteristics & No. $\left(\mathbf{\%}^{\star}\right)$ & No. (\%*) & No. $\left(\mathbf{\%}^{\dagger}\right)$ \\
\hline No & $21(9.1)$ & $209(90.9)$ & $230(78.5)$ \\
\hline $\begin{array}{l}\text { Average maintenance doses }(\mathrm{mL} / \text { day) } \\
\geq 60\end{array}$ & $18(11.5)$ & $138(88.5)$ & $156(53.2)$ \\
\hline 60 & $7(5.1)$ & $130(94.9)$ & $137(46.8)$ \\
\hline $\begin{array}{l}\text { Percentages of MMT attendance (\%) } \\
<20\end{array}$ & $1(3.2)$ & & \\
\hline $20-$ & $4(6.1)$ & $30(96.8)$ & $31(10.6)$ \\
\hline $50-$ & $4(5.2)$ & $62(93.9)$ & $66(22.5)$ \\
\hline$\geq 80 \%$ & $16(13.4)$ & $73(94.8)$ & $77(26.3)$ \\
\hline
\end{tabular}

${ }^{*}$ Calculated by row.

†Calculated by column.

study. ${ }^{25}$ Our results were based on random, long-term and consecutive urine tests, which were blind to clients in case those who continued to use heroin deliberately avoided test times.

The findings from the current analysis revealed that $91.5 \%$ of participants had used heroin at least once during the study period, which was higher than that $(75 \%)$ of general MMT clients reported by our prior study. ${ }^{25}$ The findings also showed that $14.2 \%$ almost always used heroin. Given that continued heroin use might lead to adverse health outcomes ${ }^{2023}$ and high dropout rate ${ }^{24}$ among MMT clients with HIV/AIDS, targeted interventions and control programmes are urgently needed for this subgroup.

Compared with the young participants, older clients showed greater likelihood of continued heroin use. Many older clients had turned from clinical latency stage to AIDS stage and they may experience more pain and psychological symptoms. ${ }^{29} 30$ Studies have shown that depressive symptoms are common among people with HIV infection. ${ }^{31}{ }^{32}$ However, for MMT clients, improvements in depressive symptoms and the physical domain of QOL (quality of life) among HIV-positive heroin users were poorer than in those without HIV infection. ${ }^{33}$ Also, most of them had lost the courage and confidence to live on. Culturally, stigma and discrimination towards drug use and HIV/AIDS might seriously impede MMT attendance. ${ }^{34}$ In addition, inappropriate perceptions of MMT should not be neglected.

Previous research has documented that clients who were employed were more likely to use heroin during the treatment period. ${ }^{36}$ In contrast, we found that the unemployed had more likelihood with concurrent heroin use. This was possibly due to the unemployed lacking social support and having more time to communicate with former drug-taking peers. There was a big difference between the employed and the unemployed not only in terms of sociodemographic factors but also family ties, which in turn influenced concurrent heroin use. 2537

Generally, high drug costs generally meant drug users could not afford to buy them. In our study, the clients whose financial sources depended on family or friends were less likely to use heroin. Money from family or friends is meant to support basic living and is not enough to cover drug expenditure. Furthermore, drug use and MMT is regarded as a family issue in China, and support of family or friends might potentially encourage treatment participation and compliance. ${ }^{25} 37$

There has been controversy over whether higher methadone doses could decrease heroin use among MMT clients. Studies showed an appropriate MMT dose is the most effective in suppressing heroin use during treatment. ${ }^{1838}$ Further research also suggests that an adequate dose of methadone (eg, 80-120 mg/day) would significantly reduce heroin use among clients within the first two months of treatment and eventually either eliminate or significantly curtail drug use with time in treatment. ${ }^{3940}$ However, other studies revealed there was no correlation between methadone dose and heroin use in treatment. ${ }^{414}$ The methadone dose was $\geq 60 \mathrm{mg}$ /day as recommended by the US National Institutes of Health, ${ }^{43}$ and should be higher for HIV-positive individuals. ${ }^{44}$ We found that doses of $46.8 \%$ of participants were less than $60 \mathrm{mg}$ / day and compared with those on higher doses, we did not find the clients on lower doses were more likely to use heroin. Given the small sample size and short-term observation, further research with large sample sizes and stratified doses is needed.

Without exception, treatment effectiveness relies on sufficient levels of medication adherence. MMT requires long-term or even life-long intake of methadone at an adequate dose on a daily basis. ${ }^{45}$ We found that the lower attendance meant a higher percentage of heroin use. This was consistent with our prior study. ${ }^{25}$ Clients who continued to use heroin attended MMT programmes 


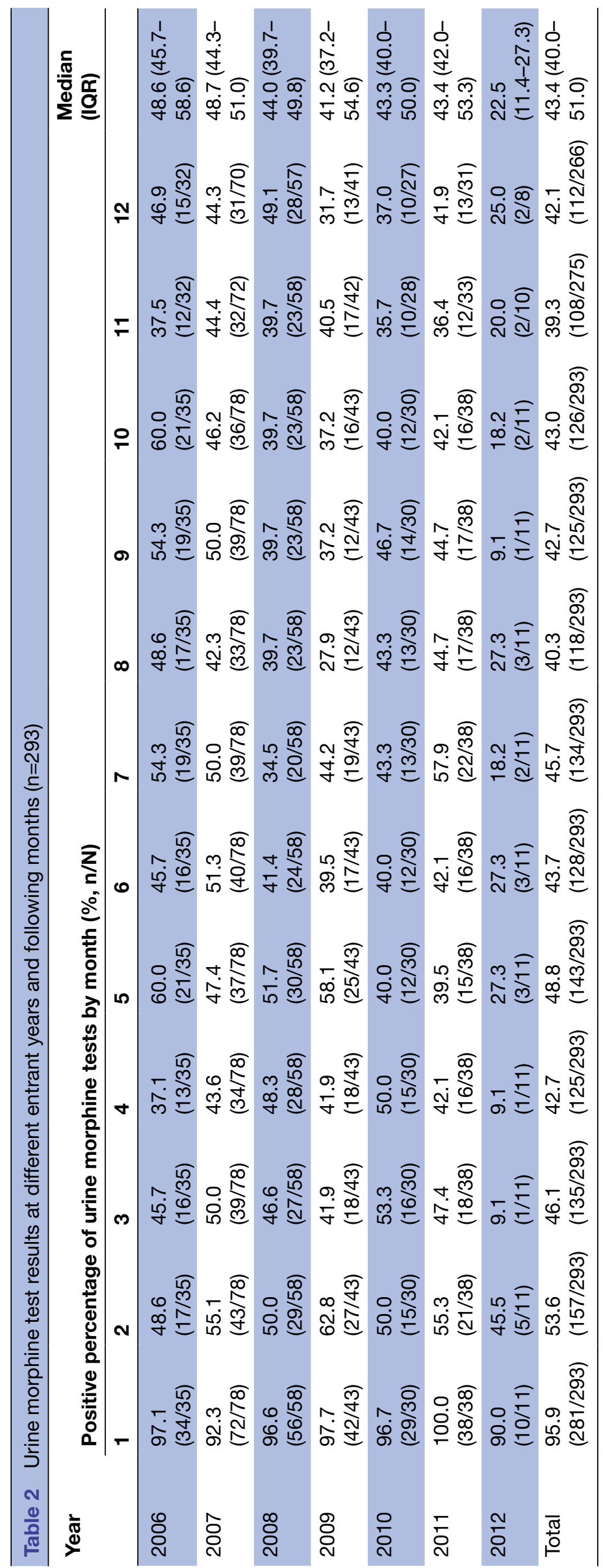


Table 3 The distribution of positive percentages of urine morphine tests among urine morphine (+) participants during the study period $(n=268)$

\begin{tabular}{lll}
\hline Positive percentage (\%) & Number (n) & Percentage (\%) \\
\hline$<10$ & 34 & 12.7 \\
$10-$ & 34 & 12.7 \\
$20-$ & 29 & 10.8 \\
$30-$ & 28 & 10.4 \\
$40-$ & 22 & 8.2 \\
$50-$ & 18 & 6.7 \\
$60-$ & 23 & 8.6 \\
$70-$ & 20 & 7.5 \\
\hline $80-$ & 22 & 8.2 \\
$90-$ & 38 & 14.2 \\
\hline Total & 268 & 100.0 \\
\hline
\end{tabular}

irregularly and the attendance significantly declined with the duration that they stayed on the treatment programme. ${ }^{46}$ Poorer attendance seeded continued heroin use. In addition, misconceptions might predict poor adherence among newly admitted MMT clients. ${ }^{47}$ So, future research might need to develop and/or integrate other necessary interventions to encourage client adherence to the treatment programme.

HIV-positive drug users have been regarded as a 'dual risk" subgroup. They transmit HIV via either sharing needles or having unprotected sexual intercourse with partners. Currently, sexual transmission is the most prevalent spread pattern of HIV/AIDS in China. ${ }^{5}$ Among the participants who finished at least once interview, $25.4 \%$ ever shared a needle; $29.2 \%$ ever had sex with multiple partners; $43.5 \%$ never used a condom; and $14.5 \%$ had sex for drugs during the study period. Considering the potential bridge role of those with dual risk behaviours in transmitting HIV to others, research on the interaction of HIV-positive MMT clients and risk behaviours should be given high priority. Data showed that changing unsafe drug use behaviours was more effective than changing unsafe sexual behaviours. ${ }^{17}$ In future treatment procedures, physicians and nurses should play an active role in educating clients about safe sex and encourage clients to use condoms.

This study is subject to certain limitations. First, self-reported data are subject to recall bias or deliberate concealment. Second, China is experiencing a significant increase in the use of new drugs, ${ }^{2}$ but this study did not consider this. In addition, we failed to obtain the ART information, and future studies should be extended to analyse ART as a predictor variable to continued heroin use. Third, we only examined the percentages of heroin use during the first 12 months after receiving MMT, and did not take $12+$ months into consideration due to the limited sample size and high dropout.
In summary, the findings from this study provide important implications for future MMT programmes targeting continued heroin use among HIV-positive clients. Concretely, first, continuous and efficient MMT consulting and health education interventions need to be conducted to reduce continued heroin use. Interventions involving family members in supervision of participation and compliance should be reinforced. Second, attendance is a crucial component affecting MMT outcomes, so how to improve sufficient attendance has become an issue of great urgency.

Acknowledgements We are grateful to the staff of MMT clinics in the study sites for their valuable assistance in subject recruitment and data collection. We appreciate the HIV-positive MMT participants who spent time with us and shared their information.

Contributors XL designed the study, performed data analysis and wrote the draft manuscript. XG and PZ performed data analysis. XZ and WC collected the data. LL supervised the study. All authors contributed to the interpretation of the data and approved the final version for submission.

Funding This study was supported by the National Natural Science Foundation of China (grant no. 71173245 and 81473065 to LL) and China Medical Board (12'111 to $\mathrm{LL}$ ).The funding agencies play no role in the study design, data collection, and data analysis, interpretation of study results and writing of the manuscript.

Competing interests None declared.

Ethics approval The Institutional Review Board (IRB) of the School of Public Health (Sun Yat-sen University, Guangzhou, China).

Provenance and peer review Not commissioned; externally peer reviewed. Data sharing statement No additional unpublished data are available.

Open Access This is an Open Access article distributed in accordance with the Creative Commons Attribution Non Commercial (CC BY-NC 4.0) license, which permits others to distribute, remix, adapt, build upon this work non-commercially, and license their derivative works on different terms, provided the original work is properly cited and the use is non-commercial. See: http://creativecommons.org/ licenses/by-nc/4.0/

(C) Article author(s) (or their employer(s) unless otherwise stated in the text of the article) 2017. All rights reserved. No commercial use is permitted unless otherwise expressly granted.

\section{REFERENCESEN}

1. Zhao M, Ling W. HIV/AIDS and drug use in China--interactions, impacts, and issues. Subst Use Misuse 2012;47:1015-25.

2. The State Council Information Office of the People's Republic of China. 2014 annual report on drug situation in China, 2014.

3 Jia M, Luo H, Ma Y, et al. The HIV epidemic in Yunnan Province, China, 1989-2007. J Acquir Immune Defic Syndr 2010;53(Suppl 1):S34-40.

4. Bao YP, Liu ZM. Systematic review of HIV and HCV infection among drug users in China. Int J STD AIDS 2009;20:399-405.

5. UNAIDS. 2014 China AIDS response progress report, 2014.

6. Wu Z. Landmark government methadone maintenance program in mainland China. "15th International AIDS Conference" 2004.

7. Yin W, Hao Y, Sun X, et al. Scaling up the national methadone maintenance treatment program in China: achievements and challenges. Int J Epidemio/ 2010;39:ii29-37.

8. Zou X, Ling L, Zhang L. Trends and risk factors for HIV, HCV and syphilis seroconversion among drug users in a methadone maintenance treatment programme in China: a 7-year retrospective cohort study. BMJ Open 2015;5:e008162.

9. Dai J, Zhao L, Liang Y. Policy implementation of methadone maintenance treatment and HIV infection: evidence from Hubei Province, China. Subst Abuse Treat Prev Policy 2013;8:38.

10. Sun HM, Li XY, Chow EP, et al. Methadone maintenance treatment programme reduces criminal activity and improves social well-being of drug users in China: a systematic review and meta-analysis. BMJ Open 2015;5:e005997. 
Table 4 Correlates of higher positive percentages among urine morphine $(+)$ participants during the study period $(n=268)$

\begin{tabular}{|c|c|c|c|c|c|}
\hline \multirow[b]{2}{*}{ Characteristics } & \multirow{2}{*}{$\begin{array}{l}<20 \%(n=68) \\
\text { No. }(\%)^{\dagger}\end{array}$} & \multirow{2}{*}{$\begin{array}{l}20-60 \%(n=97) \\
\text { No. }(\%)^{\dagger}\end{array}$} & \multirow{2}{*}{$\begin{array}{l}>60 \%(n=103) \\
\text { No. }(\%)^{\dagger}\end{array}$} & \multirow[b]{2}{*}{ OR $(95 \% \mathrm{Cl})^{*}$} & \multirow[b]{2}{*}{$p^{*}$} \\
\hline & & & & & \\
\hline \multicolumn{6}{|l|}{ Age (years) } \\
\hline$\leq 30$ & $20(32.3)$ & $28(45.2)$ & $14(22.6)$ & 0.31 (0.12 to 0.78$)$ & 0.013 \\
\hline $31-$ & $22(27.5)$ & $26(32.5)$ & $32(40.0)$ & 0.44 (0.20 to 1.00$)$ & 0.051 \\
\hline $36-$ & $13(15.7)$ & $33(39.8)$ & $37(44.6)$ & 0.91 (0.43 to 1.93$)$ & 0.814 \\
\hline$\geq 41$ & $13(30.2)$ & $10(23.3)$ & $20(46.5)$ & 1.00 & \\
\hline \multicolumn{6}{|l|}{ Gender } \\
\hline Male & $60(24.7)$ & $90(37.0)$ & $93(38.3)$ & 0.97 (0.42 to 2.22) & 0.944 \\
\hline Female & $8(32.0)$ & $7(28.0)$ & $10(40.0)$ & 1.00 & \\
\hline \multicolumn{6}{|l|}{ Marital status } \\
\hline Never married & $36(25.4)$ & $54(38.0)$ & $52(36.6)$ & 2.04 (0.92 to 4.55$)$ & 0.080 \\
\hline Married currently & $23(25.0)$ & 29 (31.5) & $40(43.5)$ & 1.93 (0.85 to 4.40$)$ & 0.117 \\
\hline Others & $9(26.5)$ & $14(41.2)$ & $11(32.4)$ & 1.00 & \\
\hline \multicolumn{6}{|l|}{ Education level } \\
\hline Elementary or lower & $16(25.4)$ & $24(38.1)$ & $23(36.5)$ & 1.50 (0.64 to 3.50$)$ & 0.347 \\
\hline Junior high school & $45(25.9)$ & $58(33.3)$ & $71(40.8)$ & 1.48 (0.71 to 3.12$)$ & 0.298 \\
\hline Senior high school or higher & $7(22.6)$ & $15(48.4)$ & $9(29.0)$ & 1.00 & \\
\hline \multicolumn{6}{|l|}{ Employment status at baseline } \\
\hline Unemployed & $45(24.2)$ & $64(34.4)$ & $77(41.4)$ & 1.99 (1.13 to 3.49$)$ & 0.017 \\
\hline Employed & $23(28.0)$ & $33(40.2)$ & $26(31.7)$ & 1.00 & \\
\hline \multicolumn{6}{|l|}{ Mainly financial sources } \\
\hline Family or friends & $49(29.0)$ & $60(35.5)$ & $60(35.5)$ & 0.55 (0.32 to 0.93$)$ & 0.025 \\
\hline Others & 19 (19.2) & $37(37.4)$ & $43(43.4)$ & 1.00 & \\
\hline \multicolumn{6}{|l|}{ Duration of drug use (years) } \\
\hline$\leq 10$ & $18(29.0)$ & $21(33.9)$ & $23(37.1)$ & 1.04 (0.50 to 2.16$)$ & 0.923 \\
\hline $11-15$ & $27(22.9)$ & $46(39.0)$ & $45(38.1)$ & $1.38(0.75$ to 2.55$)$ & 0.305 \\
\hline$\geq 16$ & $23(26.1)$ & $30(34.1)$ & $35(39.8)$ & 1.00 & \\
\hline \multicolumn{6}{|c|}{ Average times of drug use per day } \\
\hline$\leq 2$ & $21(19.3)$ & $47(43.1)$ & $41(37.6)$ & 1.03 (0.62 to 1.71$)$ & 0.912 \\
\hline$\geq 3$ & $47(29.6)$ & $50(31.4)$ & $62(39.0)$ & 1.00 & \\
\hline \multicolumn{6}{|l|}{ Shared needles at baseline } \\
\hline Yes & $38(24.8)$ & $59(38.6)$ & $56(36.6)$ & 1.03 (0.63 to 1.69$)$ & 0.902 \\
\hline No & $30(26.1)$ & $38(33.0)$ & $47(40.9)$ & 1.00 & \\
\hline \multicolumn{6}{|c|}{ Multiple sexual partners at baseline } \\
\hline Yes & $12(20.3)$ & $17(28.8)$ & $30(50.8)$ & 1.65 (0.89 to 3.05$)$ & 0.113 \\
\hline No & $56(26.8)$ & $80(38.3)$ & $73(34.9)$ & 1.00 & \\
\hline \multicolumn{6}{|c|}{ Average maintenance doses ( $\mathrm{mL} /$ day) } \\
\hline$\geq 60$ & $36(26.1)$ & $56(40.6)$ & $46(33.3)$ & $0.92(0.57$ to 1.49$)$ & 0.742 \\
\hline$<60$ & $32(24.6)$ & $41(31.5)$ & $57(43.8)$ & 1.00 & \\
\hline \multicolumn{6}{|l|}{ MMT attendance (\%) } \\
\hline$<20$ & $4(13.3)$ & $9(30.0)$ & $17(56.7)$ & 3.60 (1.55 to 8.33$)$ & 0.003 \\
\hline $20-$ & $10(16.1)$ & $19(30.6)$ & $33(53.2)$ & 2.80 (1.48 to 5.33$)$ & 0.002 \\
\hline $50-$ & $22(30.1)$ & $32(43.8)$ & $19(26.0)$ & 0.94 (0.53 to 1.67$)$ & 0.841 \\
\hline$\geq 80 \%$ & $32(31.1)$ & $37(35.9)$ & $34(33.0)$ & 1.00 & \\
\hline
\end{tabular}

*Obtained from multivariate ordinal logistic regression analysis adjusting for potential confounding variables listed in the table.

tProportions were calculated in the row. 
Table 5 Self-reported risk behaviours among urine morphine $(+)$ participants during the study period $(n=266)$

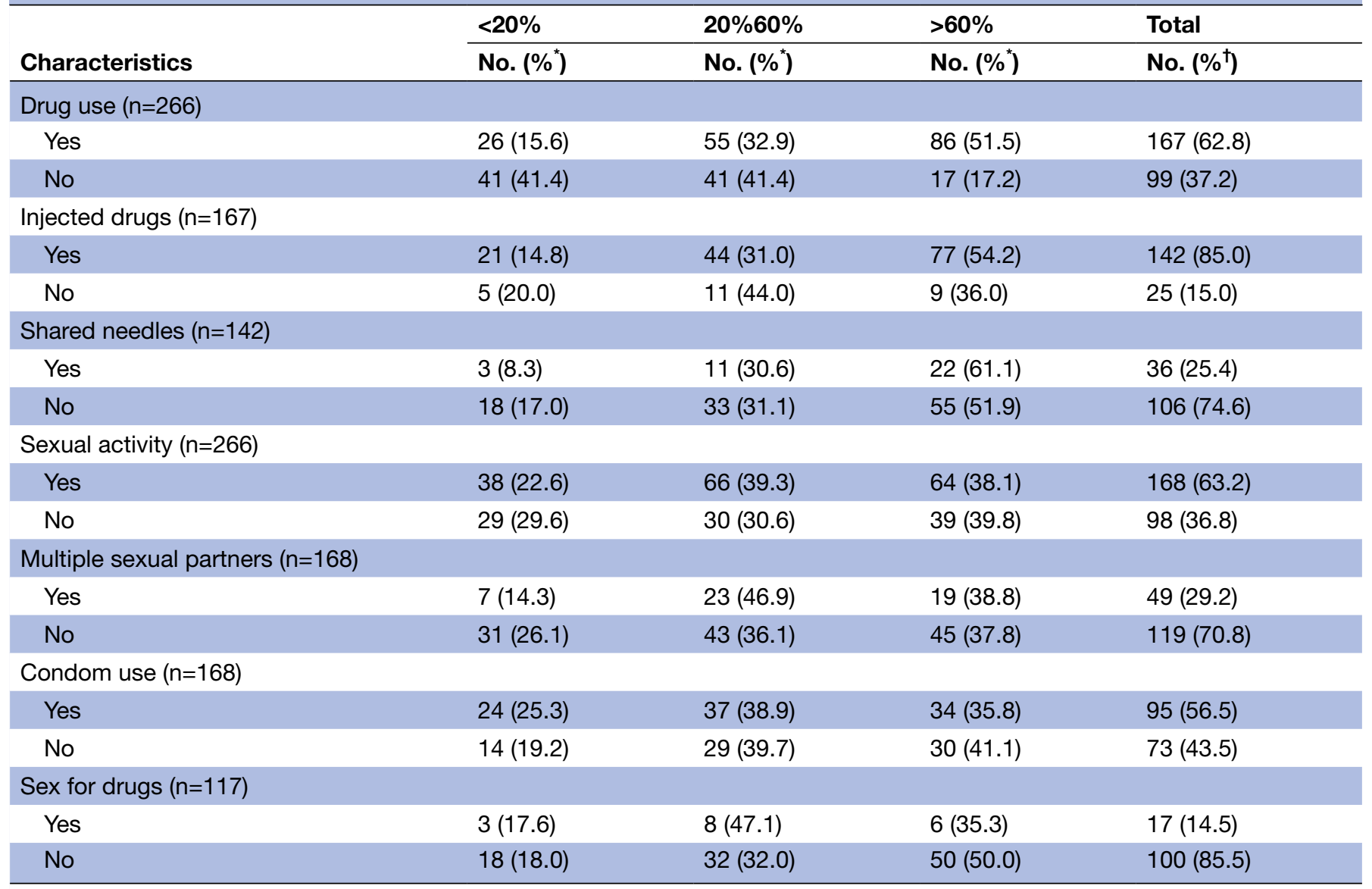

${ }^{*}$ Calculated by row.

†Calculated by column.

11. Zhao Y, Shi CX, McGoogan JM, et al. Methadone maintenance treatment and mortality in HIV-positive people who inject opioids in China. Bull World Health Organ 2013;91:93-101.

12. Reddon H, Milloy MJ, Simo A, et al. Methadone maintenance therapy decreases the rate of antiretroviral therapy discontinuation among HIV-positive illicit drug users. AIDS Behav 2014;18:740-6.

13. National Health And Family Planning Commission Of PRC. The national health and family planning commission published online 2015 http://www.nhfpc.gov.cn/zhuz/zxfb1/201506/ f2bd445f5ec04085adb9b84d995cb22b.shtml.

14. Wang $\mathrm{R}$, Ding $\mathrm{Y}$, Bai $\mathrm{H}$, et al. Illicit heroin and methamphetamine use among methadone maintenance treatment patients in Dehong prefecture of Yunnan Province, China. PLoS One 2015;10:e0133431.

15. Sullivan SG, Wu Z, Cao X, et al; National Methadone Maintenance Treatment Working Group. Continued drug use during methadone treatment in China: a retrospective analysis of 19,026 service users. $J$ Subst Abuse Treat 2014;47:86-92.

16. Li L, Lin C, Wan D, et al. Concurrent heroin use among methadone maintenance clients in China. Addict Behav 2012;37:264-8.

17. Zhang L, Chow EP, Zhuang X, et al. Methadone maintenance treatment participant retention and behavioural effectiveness in China: a systematic review and meta-analysis. PLoS One 2013;8:e68906.

18. Leri F, Bruneau J, Stewart J. Understanding polydrug use: review of heroin and cocaine co-use. Addiction 2003;98:7-22.

19. Jimenez-Treviño L, Saiz PA, García-Portilla MP, et al. A 25-year follow-up of patients admitted to methadone treatment for the first time: mortality and gender differences. Addict Behav 2011;36:1184-90.

20. McCowan C, Kidd B, Fahey T. Factors associated with mortality in Scottish patients receiving methadone in primary care: retrospective cohort study. BMJ 2009;338:b2225.

21. Darke S, Ross J, Hall W. Overdose among heroin users in Sydney, Australia: II. responses to overdose. Addiction 1996;91:413-7.
22. Darke S, Ross J, Hall W. Overdose among heroin users in Sydney, Australia: I. prevalence and correlates of non-fatal overdose. Addiction 1996;91:405-11.

23. Green TC, McGowan SK, Yokell MA, et al. HIV infection and risk of overdose: a systematic review and meta-analysis. Aids 2012;26:403-17.

24. Jiang $\mathrm{H}, \mathrm{Cao} X$, Wang $\mathrm{C}$, et al. [Study on the adherence and related determinants among HIV-positive clients under methadone maintenance treatment in dali,yunnan province from 2005 to 2013]. Zhonghua Liu Xing Bing Xue Za Zhi 2014;35:255-8.

25. Luo X, Zhao P, Gong X, et al. Concurrent heroin use and correlates among methadone maintenance treatment clients: a 12-Month Follow-up study in Guangdong Province, China. Int J Environ Res Public Health 2016;13:305.

26. NetEase. Guangdong had cumulatively reported 48,718 HIV-infected individuals, ranking fifth position in China, 2014 http://news.163. com/14/1201/06/ACC0BV8E00014AEE.html .

27. China. Com.Cn. Guangdong has the largest number of registered drug users $(457,000)$, accounting for one-sixth of the total registered drug users of China, 2014 http://news.china.com.cn/2014-11/19/ content 34094460.htm.

28. Zhang L, Zou X, Zhang D, et al. Investigation of repeat client Drop-Out and Re-Enrolment cycles in fourteen methadone maintenance treatment clinics in Guangdong, China. PLoS One 2015;10:e0139942.

29. Rodriguez-Penney AT, ludicello JE, Riggs PK, et al; HIV Neurobehavioral Research Program HNRP Group. Co-morbidities in persons infected with HIV: increased burden with older age and negative effects on health-related quality of life. AIDS Patient Care STDS 2013;27:5-16.

30. Tsao JC, Plankey MW, Young MA, Pain YMA. Pain, psychological symptoms and prescription drug misuse in HIV: a literature review. $J$ Pain Manag 2012;5:111-8. 
31. Edelman EJ, Gordon K, Becker WC, et al. Receipt of opioid analgesics by HIV-infected and uninfected patients. J Gen Intern Med 2013;28:82-90.

32. Sherr L, Clucas C, Harding R, et al. HIV and depression--a systematic review of interventions. Psychol Health Med 2011;16:493-527.

33. Wang PW, Lin HC, Yen CN, et al. Comparison of outcomes after 3-month methadone maintenance treatment between heroin users with and without HIV infection: a 3-month follow-up study. Harm Reduct J 2015;12:13.

34. Liu H, Li J, Lu Z, et al. Does chinese culture influence psychosocial factors for heroin use among young adolescents in China? A crosssectional study. BMC Public Health 2010;10:563.

35. Xu H, Gu J, Lau JT, et al. Misconceptions toward methadone maintenance treatment (MMT) and associated factors among new MMT users in Guangzhou, China. Addict Behav 2012;37:657-62.

36. Cao XB, Yin WY, Pang L, et al.Risk factors which were associated with heroin use during the methadone maintenance treatment among 1301 patients in 9 cities of China. Zhonghua Liu Xing Bing Xue Za Zhi 2010;31:269-72.

37. Lin C, Wu Z, Detels R. Family support, quality of life and concurrent substance use among methadone maintenance therapy clients in China. Public Health 2011;125:269-74.

38. Amato L, Davoli M, Perucci CA, et al. An overview of systematic reviews of the effectiveness of opiate maintenance therapies: available evidence to inform clinical practice and research. J Subst Abuse Treat 2005;28:321-9.

39. Dole VP, Nyswander ME, Kreek MJ. Narcotic blockade. 1966. J Psychoactive Drugs 1991;23. following 232.
40. Cooper JR. Ineffective use of psychoactive drugs. Methadone treatment is no exception. JAMA 1992;267:281-2.

41. Cao XB, Yin WY, Pang L, et al. [Risk factors which were associated with heroin use during the methadone maintenance treatment among 1301 patients in 9 cities of China]. Zhonghua Liu Xing Bing Xue Za Zhi 2010;31:269-72.

42. Brown BS, Watters JK, Iglehart AS. Methadone maintenance dosage levels and program retention. Am J Drug Alcohol Abuse 1982:9:129-39.

43. Conference NC. Effective medical treatment of opiate addiction. National consensus development panel on effective medical treatment of opiate addiction. JAMA 1998;280:1936-43.

44. Liu E, Rou K, McGoogan JM, et al; China's National Working Group on Methadone Maintenance Treatment. Factors associated with mortality of HIV-positive clients receiving methadone maintenance treatment in China. J Infect Dis 2013;208:442-53.

45. Mattick RP, Breen C, Kimber J, et al. Methadone maintenance therapy versus no opioid replacement therapy for opioid dependence. Cochrane Database Syst Rev 2009:CD002209.

46. Che Y, Assanangkornchai S, McNeil E, et al. Patterns of attendance in methadone maintenance treatment program in Yunnan Province, China. Am J Drug Alcohol Abuse 2011;37:148-54.

$47 \mathrm{Gu}$ J, Xu H, Lau JT, et al. Misconceptions predict dropout and poor adherence prospectively among newly admitted first-time methadone maintenance treatment clients in Guangzhou, China. Addiction 2012;107:1641-9. 